\title{
Relationship between early metabolic control and the development of microalbuminuria - a longitudinal study in children with Type 1 (insulin-dependent) diabetes mellitus
}

\author{
S. Rudberg ${ }^{1}$, E. Ullman ${ }^{2}$, G. Dahlquist ${ }^{3}$ \\ ${ }^{1}$ Department of Paediatrics, St. Göran's Childrens Hospital, Stockholm, Sweden \\ ${ }^{2}$ Department of Paediatrics, Sachs Childrens Hospital, Stockholm, Sweden \\ ${ }_{3}^{3}$ Department of Paediatrics and Department of Epidemiology, Umeå University Hospital, Sweden
}

\begin{abstract}
Summary. The cumulative incidence of microalbuminuria from onset up to 15 years of Type 1 (insulin-dependent) diabetes mellitus and the relative importance of age, duration, blood pressure and metabolic control for subsequent microalbuminuria was studied in 156 children. Urinary albumin excretion and $\mathrm{HbA}_{1 \mathrm{c}}$ were followed at 3-month intervals from onset and systolic and diastolic blood pressure at the same interval from 5 years of diabetes. Persistent microalbuminuria over $20 \mu \mathrm{g} / \mathrm{min}$ developed in 17 children. The cumulative incidence by duration was $24.2 \%$ at 15 years of diabetes. Eleven patients developed microalbuminuria after more than 5 years. Among these, first 5-year mean $\mathrm{HbA}_{1 \mathrm{c}}$ was $8.4 \pm 1.3 \%$ vs $7.2 \pm 1.1 \%$ in normoalbuminuric children ( $p<0.001)$. The crude relative risk of developing microalbuminuria with a first 5-year mean $\mathrm{HbA}_{1 \mathrm{c}}$ greater than $7.5 \%$ was 4.49 (95\% confidence interval 1.13-17.84). The age- and duration-adjusted relative risk was $3.51 \%(0.90-14.42)$. The year before transition to microalbuminuria neither mean $\mathrm{HbA}_{1 \mathrm{c}}$ nor yearly mean blood pressures, sex or age at onset of diabetes differed from normoalbuminuric children at the
\end{abstract}

same diabetes duration. Age and duration were higher $(p=0.04)$. The relative importance of early vs later hyperglycaemia, yearly blood pressures, age, age at onset and duration of diabetes for increased albumin excretion rate after more than 5 years, was shown in a multiple regression analysis where the first 5-year mean $\mathrm{HbA}_{1 \mathrm{c}}$ was the only independent predictor $(p=0.02)$. Six patients had an onset of microalbuminuria before 5 years of diabetes. In this group age, age at onset and yearly mean $\mathrm{HbA}_{1 c}$ levels did not differ from normoalbuminuric children at the same duration. We conclude that one-fourth of diabetic youth under the age of 21 years develop microalbuminuria within 14 years of diagnosis. Some patients have an early onset of microalbuminuria, not necessarily related to hyperglycaemia, while in later onset cases early hyperglycaemia is strongly related to subsequent microalbuminuria.

Key words: Type 1 (insulin-dependent) diabetes mellitus, children, microalbuminuria, cumulative incidence, metabolic control, blood pressure, microaneurysms.
The presence of microalbuminuria precedes and predicts overt diabetic nephropathy [1-4]. It is not known if persistent microalbuminuria ultimately leads to overt nephropathy, but it correlates to early glomerulopathy [5]. Thus, although other contributing factors may decide the rate of progression of diabetic renal disease, early risk factors may be the same for microalbuminuria and overt nephropathy. Some, but not all previous reports have indicated a relationship between present $\mathrm{Hb} \mathrm{A}_{1 \mathrm{c}}$ and the prevalence of microalbuminuria $[3,6-11]$. In a recent prospective study including a cohort of young diabetic patients, we found that persistent microalbuminuria developed despite improved metabolic control, between $12-$ 20 years of mean diabetes duration [12]. In patients with a diabetes duration of $10-30$ years, an $\mathrm{HbA}_{1 \mathrm{c}}$ of more than $7.5 \%$ at 5 years preceding the onset of microalbuminuria was shown to be related to the increased urinary albumin excretion rate (AER) [13]. In young patients with more than 5 years of diabetes a poor metabolic control (i.e. $\mathrm{HbA}_{1 \mathrm{c}}$ exceeding 1.5 times the upper normal) during the least 3 years was associated with a 3.6-fold prevalence of microalbuminuria [14]. Thus, a poor metabolic control early in the disease may contribute to the risk of developing persistently increased AER several years later. To the best of our knowledge, only one study has described the relationship between $\mathrm{HbA}_{1 \mathrm{c}}$ levels from the onset of diabetes and later increments in AER, but that study had only a 5-year follow up [15].

Early onset of Type 1 (insulin-dependent) diabetes mellitus (i.e. at under 20 years of age) has been reported to be associated with an increased risk of diabetic nephropathy $[16,17]$. Puberty seems to contribute to the process which leads to increments in AER $[9,18,19]$. In the present longitudinal study of young Type 1 diabetic patients under 21 years old, the cumulative incidence of microalbuminuria between $0-14$ years of diabetes duration is re- 


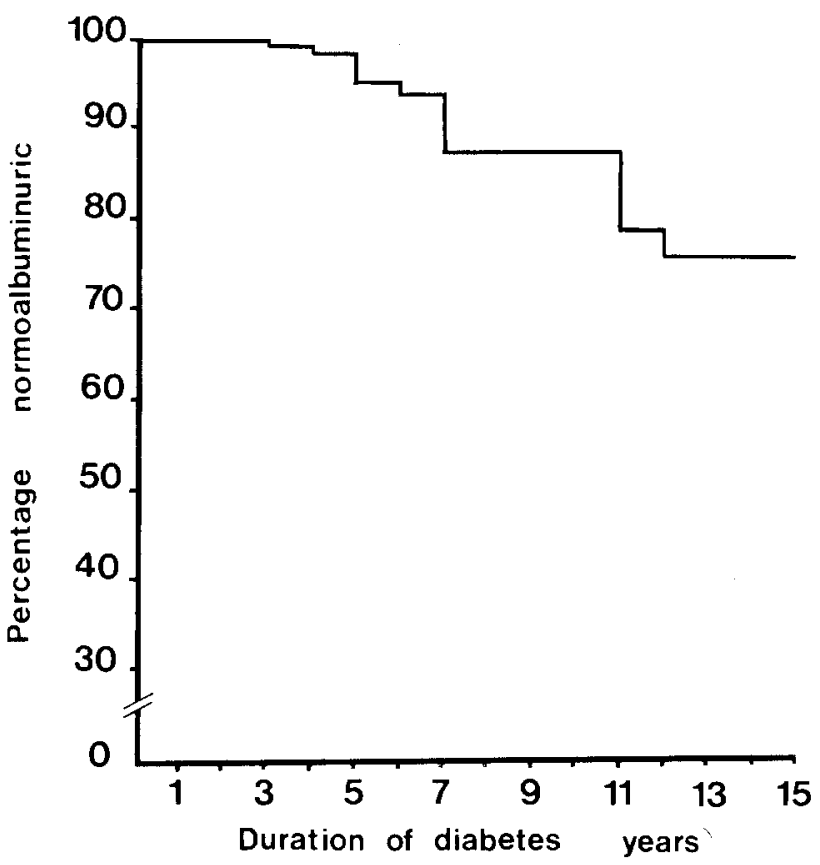

Fig. 1. Cumulative incidence of microalbuminuria from onset of diabetes until 14 years duration, in 156 children with Type 1 diabetes according to the Kaplan-Meier method of life-table estimation

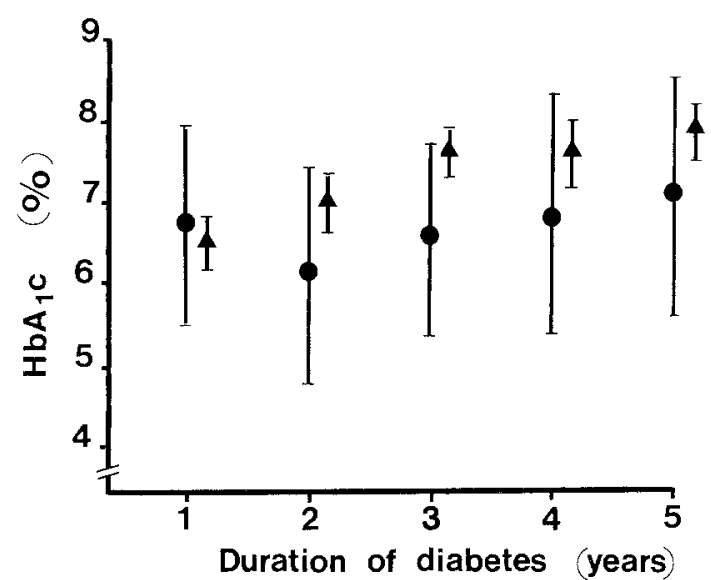

Fig. 2. Yearly mean $\mathrm{HbA}_{1 c}$ levels prior to onset of microalbuminuria in six patients with development of microalbuminuria at 5 years or less of diabetes ( $)$ as compared to levels in normoalbuminuric patients ( $\Delta$ ) at the same durations (mean, $95 \%$ confidence interval)

ported. We have also focused on the relative importance of early vs prevailing metabolic control, duration, current age and blood pressure on the occurrence of microalbuminuria as well as the association to background retinopathy.

\section{Subjects and methods}

\section{Subjects}

All children and adolescents with Type 1 diabetes ( $n=156,89$ girls/ 67 boys) whose onset occurred after September 1976 and who were still attending Sachs Children's Hospital in Stockholm on 1 July 1991, were included in this study. The mean duration of diabetes was $6.9 \pm 3.9$ years. Seventy-two patients had a diabetes duration of $0-4$ years, 49 patients, $5-9$ years and 35 patients, $10-14$ years. Mean age at onset of diabetes was $7.5 \pm 4.5$ years and current age
$14.0 \pm 3.9$ years. Of the original group 14 had moved out of the district and 17 had been referred to a department of internal medicine. These patients were not included in the statistical analysis. At Sachs Childrens Hospital all patients with Type 1 diabetes are followed-up until 20 years of age. The only selection for the recruitment of patients upon admission to hospital in Sweden (during the time of the study) was based on geographical location. All subjects were taking $2-4$ s.c. insulin doses per day and none was taking antihypertensive medication prior to the appearance of persistent microalbuminuria. Microalbuminuria was defined as a urinary AER of $20-200 \mu \mathrm{g} / \mathrm{min}$ in at least 2 of 3 consecutive urine samples [20] that was not normalized during the follow up. None of the patients had a diagnosis of renal disease unrelated to diabetes during the follow up.

\section{Procedure}

The patients were followed-up as part of a clinical routine programme from the onset of diabetes as follows: $\mathrm{HbA}_{1 \mathrm{c}}$ was analysed at 3 -month intervals since its introduction in clinical practice in 1979. It was not measured in eight patients during the first year of diabetes and nor in five patients during the second year, due to an onset of diabetes before 1979. Until $1983 \mathrm{HbA}_{1 \mathrm{c}}$ was analysed using an isoelectrical focusing technique [21] and thereafter by high-pressure liquid chromatography (Auto-A; Kyouto-Daiichi, Kagaku Co, Tokyo, Japan). The correlation between the methods was $y=x+1.5$, $r=0.84$, and all values were corrected to be in accordance to the reference level of the last mentioned method (4-6\%).

Timed overnight AER (immunoturbidimetric method; Instrumentation Lab Inc, Lexington, Mass., USA) was analysed on fresh specimens from the onset of diabetes in conjunction with $\mathrm{HbA}_{1 \mathrm{c}}$, since 1983. Therefore 27 patients were not examined regarding AER from onset, but all had normal AER levels at their first two examinations in 1983

Blood pressure was also measured at 3-month intervals from 1983 , starting at a duration of 5 years (or at 6 years in those with onset of diabetes before $1978, n=8$ ). Patients were in the supine position and the measurements were performed after 15 -min rest by the same diabetes nurse, using an automatic oscillometric device (Dinamap; Critikon, Johnson-Johnson Co., Tampa, Fla., USA). Each value recorded was the mean of four measurements.

Stereoscopic eye fundus photography was introduced in 1983, and thereafter performed by a trained ophthalmology assistant at onset and after 5, 8, 10, 12 and 14 years of diabetes duration. All photographs were analysed by the same ophthalmologist.

\section{Statistical methods}

All values are expressed as mean \pm SD (range) or $95 \%$ confidence intervals. A two-tailed $p$-value of less than 0.05 was regarded as statistically significant.

The cumulative incidence of microalbuminuria by duration was calculated using the Kaplan-Meier life-table estimation [22]. Differences in group means were evaluated by the unpaired Student's $t$-test except for comparisions of sex distribution which were evaluated by the Kolmogorov-Smirnov two sample test. Comparisons were performed between patients with and without microalbuminuria within the duration intervals of $0-4$ years and 5-14 years, respectively. The latter interval was pooled due to small numbers of patients with microalbuminuria in the duration interval of 10-14 years. When estimating the relative risk (RR) for microalbuminuria after more than 5 years with the mean $\mathrm{HbA}_{1 \mathrm{c}}$ during the first 5 years as the exposure variable, the $\mathrm{HbA}_{1 \mathrm{c}}$ was dichotomised with values of more than $7.5 \%$ as the exposed level. This level was chosen as microalbuminuria was reported to occur only in patients with $\mathrm{HbA}_{1 \mathrm{c}}$ exceeding $7.5 \%$ using a similar method with the reference level of $4.1-6.4 \%$ [13]. The adjusted RR was estimated after stratification for age and duration in 5-year intervals and was given as the Mantel-Haenszel rate ratio. The $95 \%$ confidence limits were calculated using the test-based method according to Miettinen. 
As AER had a skewed distribution the values were log-transformed prior to calculation. The Pearson method was used for single correlations. A multiple regression analysis was used to identify significant independent predictors of the degree of microalbuminuria where the whole range of log-transformed AERvalues during the last year of follow-up was used as the dependent variable.

\section{Results}

A total of 17 patients (11 girls, 6 boys) developed microalbuminuria. The cumulative incidence by duration was $24.2 \%$ up to 15 years of diabetes duration (Fig. 1), and the incidence rate was $3.0 / 100$ person-years of follow-up. No patient developed macroalbuminuria ( $>200 \mu \mathrm{g} / \mathrm{min}$ ).

\section{Onset of microalbuminuria at $0-4$ years of diabetes duration}

Six patients (five girls, one boy) were affected by microalbuminuria after a duration of $4.5(3-5)$ years at the age of $12.6 \pm 2.6$ years. In this group, patients were followed-up at a mean of 1.5 years after the onset of microalbuminuria. In only one of these patients microalbuminuria had progressed at the end of the study. The median value of AER at the final year of the study was 27 (range 21-77) $\mu \mathrm{g} / \mathrm{min}$ in this group of patients. The female predominance seen in this group was also observed in normoalbuminuric children within this duration interval (mean $3.3 \pm$ 1.6 years). Neither age at onset of diabetes nor age attained differed between these microalbuminuric and normoalbuminuric patients. Values are presented in Table 1. Systolic and diastolic blood pressure at 5 years of diabetes duration were the same in this microalbuminuric group as compared to normoalbuminuric children $(122 \pm 11 / 74 \pm$ 6 vs $125 \pm 10 / 71 \pm 7 \mathrm{~mm} \mathrm{Hg}$ ).

The yearly $\mathrm{HbA}_{1 \mathrm{c}}$ levels preceding the onset of microalbuminuria were not higher than in normoalbuminuric children at the same durations (Fig. 2).

\section{Onset of microalbuminuria at 5-14 years of diabetes duration}

Eleven subjects (six girls, five boys) developed microalbuminuria after more than 5 years of duration (mean 9.2, range 6-12 years). The mean follow-up after onset of microalbuminuria in these patients was 2 years. During this time microalbuminuria had progressed in three of the patients. The final median AER was $37(27-100) \mu \mathrm{g} / \mathrm{min}$ when regarding the whole group. The age at onset of microalbuminuria was $14.2 \pm 2.3$ years in this group. Age at onset of diabetes or sex distribution did not differ from normoalbuminuric children within this duration interval (mean $8.4 \pm 3.0$ years) but attained age was higher than in the normoalbuminuric patients $(p=0.04)$. Values for each 5-year duration interval are presented in Table 1.

The yearly mean systolic and diastolic blood pressure levels from more than 5 years until the onset of microalbuminuria were equal as in those remaining normoalbuminuric (Fig. 3).

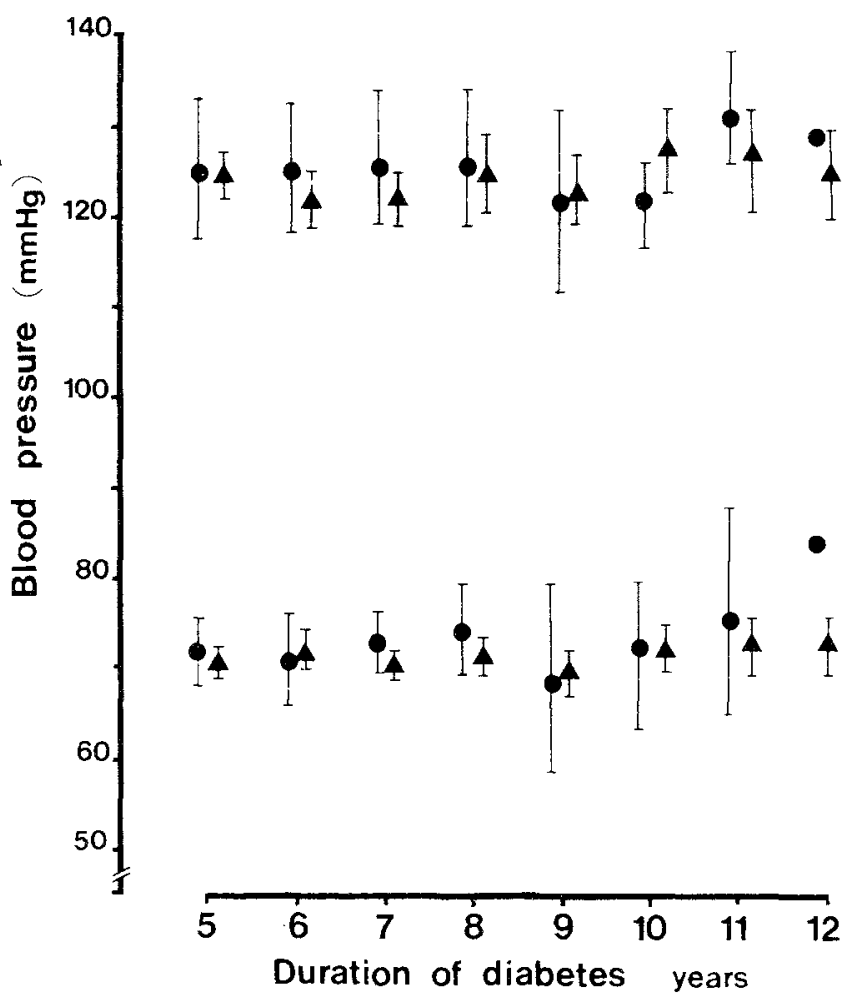

Fig.3. Yearly mean systolic and diastolic blood pressures in 11 patients with onset of microalbuminuria after more than 5 years ( $)$ and in normoalbuminuric children at the same durations (A). Levels presented as mean, $95 \%$ confidence interval

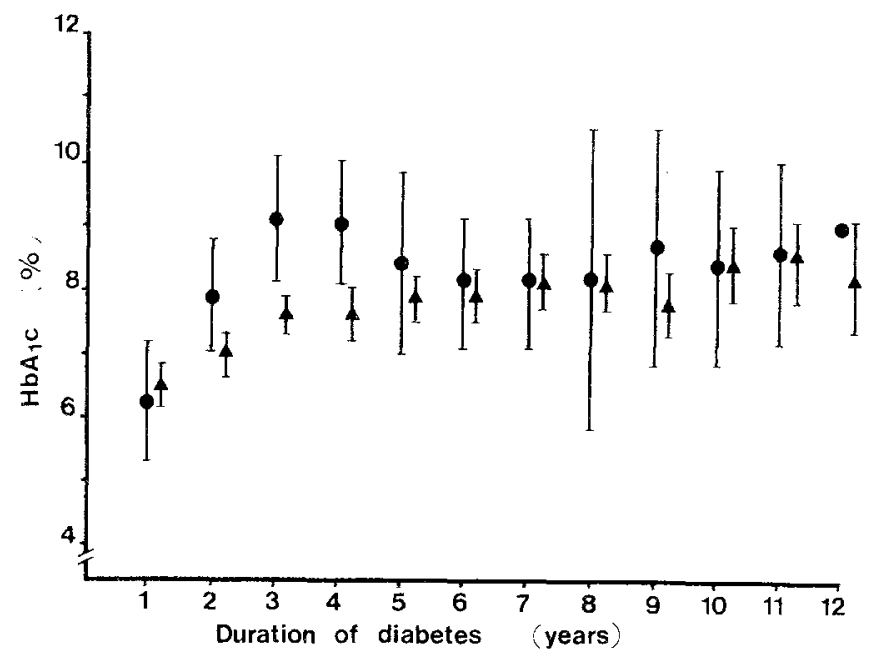

Fig.4. Yearly mean $\mathrm{HbA}_{1 c}$ values in 11 patients prior to the onset of microalbuminuria after more than 5 years $(\bullet)$ as compared to normoalbuminuric subjects ( $\boldsymbol{A}$ ) at the same durations (mean, $95 \%$ confidence interval)

In subjects with elevated $\mathrm{AER}$ the yearly $\mathrm{HbA}_{1 \mathrm{c}}$ values of the first 5 years of diabetes tended to be higher than in normoalbuminuric patients, but significantly so only at 3 and 4 years of duration $(p=0.02$ respectively, Fig. 4$)$. The $\mathrm{HbA}_{1 \mathrm{c}}$ the year before transition to microalbuminuria did not differ from patients with normal AER at the same duration (Fig. 4).

The $\mathrm{HbA}_{1 \mathrm{c}}$ during the first 5 years of diabetes was $8.4 \pm 1.3 \%$ in microalbuminuric vs $7.2 \pm 1.1$ in normoalbuminuric children $(p<0.001)$. The crude RR of developing microalbuminuria between 5-14 years with a mean $\mathrm{HbA}_{1 c}$ 
Table 1. Sex distribution, age at onset of diabetes, attained age and mean $\mathrm{HbA}_{1 \mathrm{c}}$ during the first 5 years of diabetes in patients with microalbuminuria (MA) and normoalbuminuria (NA) within the diabetes duration intervals of 0-4, 5-9 and 10-14 years

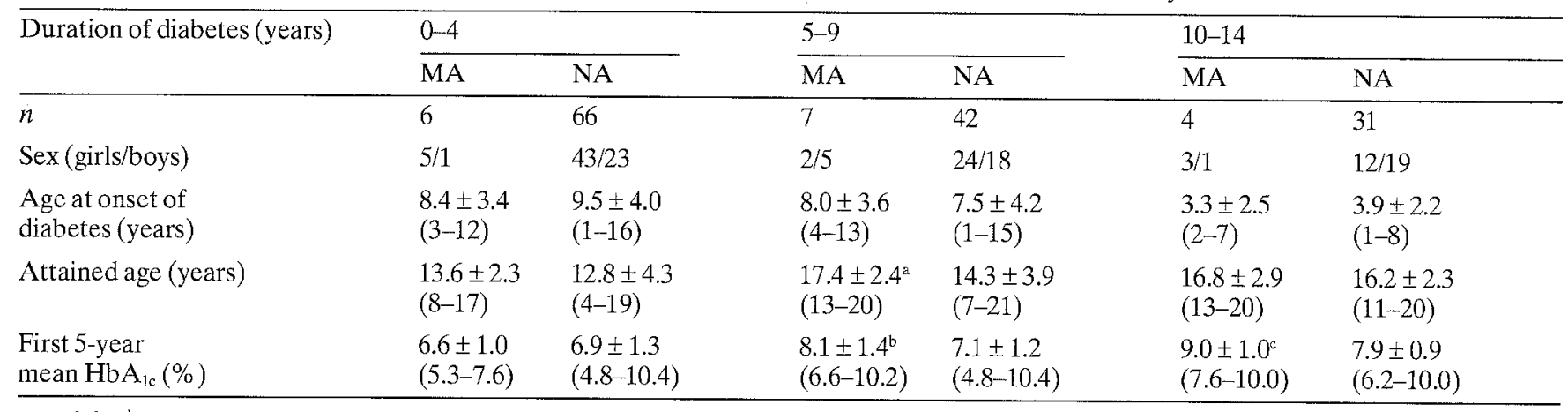

${ }^{\mathrm{a}} p=0.03,{ }^{\mathrm{b}} p=0.04,{ }^{\mathrm{c}} p<0.001$ Microalbuminuric vs normoalbuminuric children. Values are given as mean $\pm \mathrm{SD}$ (range)

of more than $7.5 \%$ during this early period, was $4.49(95 \%$ confidence interval 1.13-17.84). There was a correlation between current age and $\mathrm{HbA}_{1 \mathrm{c}}, r=0.28, p=0.04$ as well as between age and microalbuminuria, $r=0.32, p=0.02$. Therefore age had been taken into account as a possible confounder and the age adjusted RR was 3.51 (95\% confidence interval 0.90-14.42). Current age and diabetes duration were closely related $(r=0.40, p<0.001)$ and stratification for duration did not further affect the RR. When using the upper quartile level of first 5-year mean $\mathrm{HbA}_{1 \mathrm{c}}$, which was $8.0 \%$, as the dichotomised level the RR to get microalbuminuria was essentially the same; crude RR 3.97 (1.02-12.27) and adjusted RR 3.04 (0.84-10.95).

In a multiple regression analysis the $\mathrm{HbA}_{1 \mathrm{c}}$ during the first 5 years of diabetes was found to be the only variable with an independent significant influence on $\log$ AER during the last year of follow up (standard regression coefficient $=0.29, p=0.01$ ). This regression analysis also included mean yearly $\mathrm{HbA}_{1 \mathrm{c}}$ values from more than 5 years of diabetes duration up to the onset of microalbuminuria, yearly mean blood pressures, duration of diabetes, current age and age at onset of diabetes. The current age was marginally significant in this model (standard regression coefficient $=0.22, p=0.06$ ) .

\section{Background retinopathy}

Nine patients exhibited microaneurysms during followup. Six of them had microalbuminuria and the other three were still normoalbuminuric at the final examination. No patient had proliferative changes.

In those with microalbuminuria, background retinopathy appeared after a mean duration of $8.0 \pm 2.6$ (range 5-14) years. Two of them had the microaneurysms diagnosed 2 years prior to onset of microalbuminuria, one at the same time, two patients 1 year after and one patient 3 years after. The microaneurysms disappeared at followup in two patients in the microalbuminuric group and one in the normoalbuminuric.

Patients with microaneurysms had a higher mean $\mathrm{HbA}_{1 \mathrm{c}}$ during the first 5 years of diabetes than those without $(8.4 \pm 1.1$ vs $7.3 \pm 1.2 \%, p=0.01)$ and the relationship between these variables was $r=0.32, p=0.02$. The presence of microaneurysms was not correlated with current $\mathrm{HbA}_{1 \mathrm{c}}$, mean yearly blood pressure levels or age at onset of diabetes. Microalbuminuria was associated with the occurrence of microaneurysms $(r=0.26, p=0.05)$, as was diabetes duration $(r=0.47, p<0.001)$ and current age $(r=0.23, p=0.06)$.

\section{Discussion}

In the present cohort of diabetic patients who were young at onset of disease, the cumulative incidence of microalbuminuria was about $25 \%$ at 15 years of duration. The proportion of Type 1 diabetic patients with persistent microalbuminuria (or incipient nephropathy, i.e. AER 20$200 \mu \mathrm{g} / \mathrm{min}$ ) that will progress to overt nephropathy is still not clearly defined. It has been shown that some patients, mainly in the lower range of microalbuminuria, do not increase their AER during a shorter follow-up, i.e. 24 years $[8,23,24]$. Nevertheless, it appears to be established that the development of microalbuminuria is associated with progressing glomerular structural changes [5]. The incidence rates of elevated AER found in our study are only slightly lower than those reported for overt nephropathy $[16,25,26]$ but may reflect a declining risk of diabetic nephropathy. However, it cannot be excluded that the cumulative incidence of microalbuminuria may increase if patients with a diabetes duration of more than 14 years are included.

The idea that hyperglycaemia is a prerequisite for nephropathy is widely accepted $[25,27,28]$. Patients with the most frequent severe hyperglycaemia during the first 15 years of diabetes were reported to have a 4.5 -fold risk for overt nephropathy [25]. In our study neither the mean $\mathrm{HbA}_{1 \mathrm{c}}$ after more than 5 years of diabetes was significantly associated with increased AER, nor was the mean $\mathrm{HbA}_{1 \mathrm{c}}$ the year preceding the onset of microalbuminuria. This is in accordance with the findings of our previous prospective longitudinal study where we found that $\mathrm{HbA}_{1 \mathrm{c}}$ after more than 8 years of diabetes did not predict the occurrence of microalbuminuria [12]. On the other hand, Mathiesen et al. [13] have shown that in patients with a diabetes duration between $10-30$ years, persistently elevated AER occurred only in those whose $\mathrm{HbA}_{1 \mathrm{c}}$ exceeded $7.5 \%$ at 5 years preceding the onset of microalbuminuria. In the present study poor glycaemic control during the first 5 years of diabetes was associated with later increases in AER ( $>5$ years). Although some pa- 
tients had sustained hyperglycaemia, $\mathrm{HbA}_{1 \mathrm{c}}$ levels tended to decrease during the years before transition to microalbuminuria. Acute as well as chronic mechanisms for the deleterious effect of high blood glucose on renal tissue have been proposed. An enhanced glucose flux through the polyol pathway with accumulation of toxic polyols is suggested [29]. The formation of advanced glycation endproducts may also be responsible for changes in vascular permeability as well as matrix overproduction causing irreversible cross-linking of proteins that may damage the glomerular ultrastructure [30]. These hypotheses are in agreement with findings that microangiopathy may develop despite restore euglycaemia $[31,32]$. However, our observation of high mean $\mathrm{HbA}_{1 \mathrm{c}}$ during the first 5 years as the main independent predictor for later increases in AER does not necessarily indicate a "point of no return". Even if the early hyperglycaemia is of a relatively greater importance in this young age group, clearly a prolonged duration of poor metabolic control may still affect the progression of the renal damage as indicated by several intervention studies in patients with increased AER $[8,23]$.

It has been reported previously that age has an influence on AER levels independently of the diabetes duration in children and adolescents $[9,18]$. In the present study, current age was the other factor (in addition to early hyperglycaemia) that showed a marginally significant and independent relationship to the degree of microalbuminuria after more than 5 years of diabetes, also when duration of diabetes was taken into account. In this group of patients elevated AER was not seen before 12 years of age. Puberty seems to be a critical period for the initiation of diabetic renal affection $[9,10,18]$. Insulin resistance and hyperglycaemia together with changes in levels of sex steroids, increments in growth hormone and accelerated growth may be possible precipitating factors for incipient nephropathy in young susceptible individuals [33].

A prolonged elevated blood glucose is obviously not sufficient to cause microalbuminuria as several patients, in this as well as in other studies, exhibited marked hyperglycaemia without developing microalbuminuria. An interaction of several factors, such as genetic predisposition $[34,35]$ and haemodynamic changes [12] may possibly contribute to the development of diabetic renal disease. It is still being debated whether increased susceptibility for diabetic nephropathy is related to family history of hypertension $[36,37]$. Diabetic renal disease may share some risk markers with essential hypertension [33, 35]. This does not necessarily preclude the presence of increased blood pressure prior to the development of microalbuminuria. Two independent studies investigating the time relation between onset of microalbuminuria and elevation of blood pressure found that persistent microalbuminuria precedes increases in blood pressure with 23 years $[12,13]$. However, in these studies blood pressure was only recorded annually or every second year and measured to the nearest $5 \mathrm{~mm} \mathrm{Hg}$. Thus, smaller but still important elevations may have been missed. In the present study this was avoided by taking measurements using an automatic device at 3-month intervals. We could thus confirm that yearly mean blood pressure levels from 5 years of diabetes onward were within the normal range for age and sex [38] and did not differ between patients of the same diabetes duration with normoalbuminuria and those who later developed microalbuminuria.

In young patients with Type 1 diabetes microalbuminuria is seen mainly after more than 5 years of duration and in children older than 12 years of age $[9,10,19]$. Therefore, routine screening is recommended after this age and duration in diabetic children [39]. However, some patients with an earlier onset of microalbuminuria have been reported in cross-sectional studies of children and adolescents $[9,10]$. We identified 6 of 72 patients with increased AER between 3-5 years diabetes duration and three of these had microalbuminuria before 12 years of age. This may suggest that screening for microalbuminuria should be started at an earlier duration as well as age. In this group of patients we found no association between metabolic control and the development of microalbuminuria within the first 5 years of diabetes. This is partly congruent with results from an earlier report of microalbuminuria at 5 years duration, which showed no relation to 5 -year mean $\mathrm{HbA}_{1 \mathrm{c}}$ in young boys but in girls [15]. The patients with a very early onset of microalbuminuria in our study seem to represent a specific subgroup of the microalbuminuric children who also tend to differ from those with later onset of microalbuminuria, with regard to sex distribution and age at onset of microalbuminuria. This may be speculated to reflect a greater genetic susceptibility to renal changes in this group of patients. However, it cannot be excluded that microalbuminuria may not necessarily be related to progressing diabetic glomerulopathy in these patients. A longer follow-up is necessary to evaluate the significance of the microalbuminuria in these subjects.

The natural history of nephropathy and retinopathy are thought to be closely connected. Patients with clinical signs of nephropathy also usually have proliferative retinopathy [40]. A higher prevalence of retinopathy has also been reported in children with Type 1 diabetes and microalbuminuria [41]. Although several microalbuminuric patients in our study exhibited no retinal changes there was a correlation between the occurrence of background retinopathy and increased AER. However, no temporal relationship between these two factors could be established.

In conclusion, approximately one-fourth of diabetic youth under 21 years of age may be at risk of developing diabetic nephropathy. Poor metabolic control during the first years of diabetes greatly increases the subsequent risk of incipient nephropathy. Pubertal age may also affect the onset of microalbuminuria. In rare instances, microalbuminuria develops before 5 years of diabetes duration. However, this group of patients is different as no obvious relationship appears to exist to the degree of metabolic control or age.

Acknowledgements. This study was supported by grants from the Swedish Medical Research Council, project no 07351. We also wish to thank diabetes nurse Ms. A. Ahlborg-Carlsson for invaluable assistance. 


\section{References}

1. Viberti GC, Hill RD, Jarrett RJ, Argyropoulos A, Mahmud U, Keen H (1982) Microalbuminuria as a predictor of clinical nephropathy in insulin-dependent diabetes mellitus. Lancet I: $1430-1432$

2. Mogensen CE, Christensen CK (1984) Predicting diabetic nephropathy in insulin-dependent diabetes. N Engl J Med 311: 89 93

3. Mathiesen ER, Oxenbøll B, Johansen K, Svendsen PA, Deckert $T$ (1984) Incipient nephropathy in type 1 (insulin-dependent) diabetes. Diabetologia 26: 406-410

4. Messent J, Elliot T, Hill R, Jarrett J, Keen H, Viberti GC (1992) Prognostic significance of microalbuminuria in insulin-dependent diabetes mellitus: a twenty-three year follow-up study. Kidney Int 41: 836-839

5. Walker J, Close C, Jones S et al. (1991) Glomerular structure in type-1 (insulin-dependent) diabetic patients with normo- and microalbuminuria. Kidney Int 41: 741-748

6. Wiseman M, Viberti G, Mackintosh D, Jarrett RJ, Keen H (1984) Glycaemia, arterial pressure and micro-albuminuria in type 1 (insulin-dependent) diabetes mellitus. Diabetologia 26: 401-405

7. Parving H-H, Hommel E, Mathiesen E et al. (1988) Prevalence of microalbuminuria, arterial hypertension, retinopathy and neuropathy in patients with insulin-dependent diabetes. BMJ 296: $156-160$

8. Feldt-Rasmussen B, Mathiesen ER, Deckert T (1986) Effect of two years of strict metabolic control on progression of incipient nephropathy in insulin-dependent diabetes. Lancet II: 13001304

9. Dahlquist G, Rudberg S (1987) The prevalence of microalbuminuria in diabetic children and adolescents and its relation to puberty. Acta Paediatr Scand 76: 795-800

10. Mathiesen ER, Saurbrey N, Hommel E, Parving H-H (1986) Prevalence of microalbuminuria in children with type 1 (insulindependent) diabetes mellitus. Diabetologia 29:640-643

11. Berglund J, Lins P-E, Adamson U, Lins L-E (1987) Microalbuminuria in long-term insulin-dependent diabetes mellitus. Acta Med Scand 222: 333-338

12. Rudberg S, Persson B, Dahlquist G (1992) Increased glomerular filtration rate as a predictor of diabetic nephropathy - An 8-year prospective study. Kidney Int 41: 822-828

13. Mathiesen ER, Ronn B, Jensen T, Storm B, Deckert T (1990) Relationship between blood pressure and urinary albumin excretion in development of microalbuminuria. Diabetes 39: 245-249

14. Chase HP, Jackson WE, Hoops SL, Cockerham RS, Archer PG, O'Brien D (1989) Glucose control and the renal and retinal complications of insulin-dependent diabetes. JAMA 261: 1155-1160

15. D'Antonio J, Ellis D, Doft B et al. (1989) Diabetes complications and glycemic control. The Pittsburgh prospective insulin-dependent diabetes cohort study status report after $5 \mathrm{yr}$ of IDDM. Diabetes Care 12: 694-700

16. Kofoed-Enevoldsen A, Borch-Johnsen K, Kreiner S, Nerup J, Deckert $T$ (1987) Declining incidence of persistent proteinuria in type-1 (insulin-dependent) diabetic patients in Denmark. Diabetes 36:205-209

17. Parving H-H, Hommel E, Damkjaer Nielsen M, Giese J (1988) Prevalence of microalbuminuria, arterial hypertension, retinopathy and neuropathy in patients with insulin-dependent diabetes. BMJ 299: 533-536

18. Salardi S, Cacciari E, Pascucci G et al. (1990) Microalbuminuria in diabetic children and adolescents. Acta Paediatr Scand 79: 437-443

19. Mortensen HB, Marinelli K, Norgaard K et al. (1990) A nationwide cross-sectional study of urinary albumin excretion rate, arterial blood pressure and blood glucose control in Danish children with type-1 diabetes mellitus. Diabetic Med 7: 887-897

20. Mogensen CE, Cachati A, Christensen CK et al. (1985-86) Microalbuminuria: an early marker of renal involvement in diabetes. Uremia Invest 9: 85-95

21. Jeppson JO, Franzen B, Gaal AB (1980) Simplified determination of hemoglobin A1c in diabetic patients by use of electrofocus- ing. In: Radola BJ (ed) Electrophoresis: Advanced methods: Biochemical and clinical applications. de Gruyter, Berlin, pp 59-61

22. Pocock SJ (1991) Clinical trials. A practical approach. Wiley, New York, pp 221-224

23. Dahl-Jorgensen K, Hanssen K, Kierulf P, Bjoro T, Sandvik L, Aagenaes O (1988) Reduction of urinary albumin excretion after 4 years of continuous subcutaneous insulin infusion in insulindependent diabetes mellitus. Acta Endocrinol 117: 19-25

24. Feldt-Rasmussen B, Jensen T, Lauritzen T, Mathiesen ER, Deckert T (1991) Effect of poor metabolic control on loss of kidney function in type 1 (insulin-dependent) diabetic patients: an update of the Steno studies. Diabetologia 34: 164-170

25. Krolewski A, Warram J, Chriestlieb R, Busick E, Kahn R (1985) The changing natural history of nephropathy in type 1 diabetes. Am J Med 318: 140-145

26. Andersen AR, Sandahl Christiansen J, Andersen JK, Kreiner S, Deckert T (1983) Diabetic nephropathy in type 1 (insulin-dependent) diabetes: an epidemiological study. Diabetologia 25: 496-501

27. Pirart J (1978) Diabetes mellitus and its degenerative complications: a prospective study of 4400 patients observed between 1947 and 1973. Diabetes Care 1: 168-188

28. Hasslacher CM, Stech W, Wahl P, Ritz E (1985) Blood pressure and metabolic control as risk factors for nephropathy in type 1 (insulin-dependent) diabetes. Diabetologia 28: 6-11

29. Greene DA, Lattimer SA, Sima AAF (1987) Sorbitol, phosphoinositide and the sodium-potassium ATPase in the pathogenesis of diabetic complications. N Engl J Med 316:599-606

30. Vlassara H, Brownlee M, Cerami A (1986) Nonenzymatic glycosylation: role in the pathogenesis of diabetic complications. Clin Chem 32 [Suppl 10]: B37-B 48

31. Ramsay RC, Goetz FC, Sutherland DER et al. (1988) Progression of diabetic retinopathy after pancreas transplantation for insulin-dependent diabetes mellitus. N Engl J Med 318: 208-214

32. Engerman RL, Kern TS (1987) Progression of incipient diabetic retinopathy during good glycemic control. Diabetes 36: 808-812

33. Lunbaeck K, Christensen NJ, Jensen VA et al. (1970) Diabetes, diabetic angiopathy and growth hormone. Lancet II: 131-133

34. Deckert T, Feldt-Rasmussen B, Borch-Johnsen K, Jensen T, Kofoed-Enevoldsen A (1989) Albuminuria reflects widespread vascular damage. The Steno hypothesis. Diabetologia 32: 219-226

35. Barzilay J, Warram JH, Bak M, Laffel LMB, Canessa M, Krolewski A (1992) Predisposition to hypertension: risk factor for nephropathy and hypertension in IDDM. Kidney Int 41: 723-730

36. Jensen JS, Mathiesen ER, Nørgaard K et al. (1990) Increased blood pressure and erythrocyte sodium/lithium countertransport activity are not inherited in diabetic nephropathy. Diabetologia 33: 619-624

37. Mangili R, Bending JJ, Scott G, Li LK, Gupta A, Viberti GC (1988) Increased sodium-lithium countertransport activity in red cells of patients with insulin-dependent diabetes and nephropathy. N Engl J Med 318: 146-150

38. National Heart, Lung and Blood Institute (1977) Report on the Task Force on Blood Pressure Control in Children. Pediatrics 59: [Suppl] 803

39. Krans HMJ, Porta M, Keen H (1992) Diabetes care and research in Europe: the St Vincent Declaration action programme. WHO, Geneva, pp 29-32

40. Vigstrup J, Mogensen CE (1985) Proliferative diabetic retinopathy: at risk patients identified by early detection of microalbuminuria. Acta Ophthalmol 63: 530-534

41. Nørgaard K, Storm B, Graae M, Feldt-Rasmussen B (1989) Elevated albumin excretion and retinal changes in children with type 1 diabetes are related to long-term poor blood glucose control. Diabetic Med 6: 325-328

Received: 30 March 1993

and in revised form: 2 July 1993

Dr. S. Rudberg

Department of Paediatrics

St. Göran's Chilđrens Hospital

S-11281 Stockholm, Sweden 